\title{
Nutritional intervention in cognitively impaired geriatric trauma patients: a feasibility study
}

\author{
This article was published in the following Dove Press journal: \\ Clinical Interventions in Aging \\ 12 September 2016 \\ Number of times this article has been viewed
}

\section{Eschbach' \\ T Kirchbichler' \\ TWiesmann ${ }^{2}$ \\ L Oberkircher' \\ C Bliemel' \\ S Ruchholtz' \\ B Buecking'}

'Center for Orthopedics and Trauma Surgery, ${ }^{2}$ Department of Anaesthesiology and Critical Care, University of Marburg, Marburg, Germany
Correspondence: D Eschbach Center for Orthopedics and Trauma Surgery, University of Marburg, Baldingerstrasse, D-35033 Marburg, Germany Tel +49 642I 5863544

Email eschbach@med.uni-marburg.de
Background: Most studies focusing on improving the nutritional status of geriatric trauma patients exclude patients with cognitive impairment. These patients are especially at risk of malnutrition at admission and of worsening during the perioperative fasting period. This study was planned as a feasibility study to identify the difficulties involved in including this high-risk collective of cognitively impaired geriatric trauma patients.

Patients and methods: This prospective intervention study included cognitively impaired geriatric patients (Mini-Mental State Examination $<25$, age $>65$ years) with hip-related fractures. We assessed Mini Nutritional Assessment (MNA), Nutritional Risk Screening (NRS 2002), body mass index, calf circumference, American Society of Anesthesiologists' classification, and Braden Scale. All patients received parenteral nutritional supplementation of $800 \mathrm{kcal} / \mathrm{d}$ for the 96 -hour perioperative period. Serum albumin and pseudocholinesterase were monitored. Information related to the study design and any complications in the clinical course were documented.

Results: A total of 96 patients were screened, among whom eleven women (median age: 87 years; age range: 74-91 years) and nine men (median age: 82 years; age range: $73-89$ years) were included. The Mini-Mental State Examination score was 9.5 (0-24). All patients were manifestly undernourished or at risk according to MNA and NRS 2002. The body mass index was $23 \mathrm{~kg} / \mathrm{m}^{2}\left(13-30 \mathrm{~kg} / \mathrm{m}^{2}\right)$, the calf circumference was $29.5 \mathrm{~cm}(18-34 \mathrm{~cm})$, and the mean American Society of Anesthesiologists' classification status was 3 (2-4). Braden Scale showed 18 patients at high risk of developing pressure ulcers. In all, 12 patients had nonsurgical complications with $10 \%$ mortality. Albumin as well as pseudocholinesterase dropped significantly from admission to discharge. The study design proved to be feasible.

Conclusion: The testing of MNA and NRS 2002 was feasible. Cognitively impaired trauma patients proved to be especially at risk of malnutrition. Since 96 hours of parenteral nutrition as a crisis intervention was insufficient, additional supplementation could be considered. Laboratory and functional outcome parameters for measuring successive supplementation certainly need further evaluations involving randomized controlled trials.

Keywords: malnutrition, perioperative nutrition management, elderly, cognitive impaired geriatric trauma patients

\section{Introduction}

Owing to demographic changes, malnutrition is a continuing source of concern among older people. ${ }^{1,2}$ Data show that up to $55 \%$ of elderly hospitalized patients and up to $58 \%$ of patients with a hip fracture are undernourished on admission. ${ }^{3-6}$ Perioperative medical complications, perioperative periods of prolonged fasting while waiting for surgical treatment, and preexisting dementia may also restrict nutritional intake in the perioperative phase. ${ }^{7,8}$ It is estimated that $\sim 30 \%$ of patients who sustain a hip 
fracture also have cognitive impairment..$^{9-11}$ We know that, especially in cognitively impaired patients, oral food intake is challenging. During dementia progression, patients may no longer know what they are supposed to do with the food, and their eating skills are lost. ${ }^{12}$ Thus, weight loss is a prominent clinical feature of dementia. ${ }^{13,14}$ There is evidence that the association between dementia and weight loss increases in the more severe stages of dementia. ${ }^{15}$ There is also some evidence that a low body mass index (BMI) is associated with reduced survival and that older patients with dementia benefit from higher BMIs. ${ }^{16,17}$

For a large number of patients, poor nutritional status represents an underlying cause of falls and fractures. ${ }^{18}$ According to a study by Eneroth et al, ${ }^{19}$ the intake of energy during hospital stays is considerably lower than is needed. Postfracture loss of body mass and muscle strength causes further impairment of already impaired muscle function. ${ }^{3}$ Furthermore, malnutrition has a strong negative impact on wound healing ${ }^{20,21}$ and is associated with prolonged hospital stays and higher mortality rates. ${ }^{22}$ Thus, the improvement of patients' nutritional status could help optimize care for geriatric trauma patients.

Many of the studies focusing on improving the nutritional status of geriatric trauma patients exclude patients with dementia or other kinds of cognitive impairment. , $^{8,23}$ This is a common problem; in a recent review dealing with hip fracture patients, only 19 of 72 randomized controlled trial studies included both cognitively intact and impaired patients and only 14 reported the use of a validated cognitive assessment tool. ${ }^{24}$

However, these patients are of particular interest, as they are at maximum risk of having malnutrition at admission and of worsening during the perioperative period. Studies focusing on nightly tube feeding have shown inconsistent results but have matched the reporting about some patients' poor tolerance of nasogastric tubes. ${ }^{25,26}$ In the mentioned investigations, $25 \%-82 \%$ of included patients did not tolerate tubes until the end point of intervention. The European Society for Clinical Nutrition and Metabolism (ESPEN) guidelines on nutrition in dementia ${ }^{27}$ suggest parenteral nutrition if there is an indication for artificial nutrition but tube feeding is contraindicated or not tolerated, if the period is shorter than 10 days, or if central venous line is already in place for other reasons.

In this pilot study, we assessed a treatment of 96 hours of perioperative parenteral nutrition with standardized energy intake in a sample of cognitively impaired geriatric hip fracture patients who were undernourished or at risk of malnutrition. This study was planned as a feasibility study to detect the specific problems and difficulties related to screening, inclusion, nutritional intervention, and outcome measurement in this fragile, high-risk group of cognitively impaired geriatric trauma patients.

\section{Patients and methods}

The study was approved by the local ethics committee of the Philipps University of Marburg (Ethikkomission der Universität Marburg), and written informed consent was obtained from participants or from their legal guardians.

The screening procedure of this prospective singlecenter intervention study included all geriatric patients (age 60 years or older) with proximal femoral fractures (ICD 10 S 72.0-72.2) admitted to our emergency department. The exclusion criteria were pathological fractures or malignancy-associated fractures, multiple traumas, contraindications for parenteral nutrition (such as a soy protein or peanut allergy), and severe liver impairment.

We included all patients identified as being cognitively impaired by Mini-Mental State Examination $(<25)^{28}$ in our prospective study design. Subsequently, we used two screening questionnaires, the Mini Nutritional Assessment (MNA) Elderly and the 2002 version of the Nutritional Risk Screening (NRS 2002) to detect malnutrition. We also measured patients' BMI, calf circumference (CC), prefracture Barthel Index, and American Society of Anesthesiologists' classification status. ${ }^{29}$ The type of surgery (osteosynthesis or prosthesis) and the lengths of the patients' stays in the intensive care unit and in the hospital were documented.

If patients were identified as being at risk of malnutrition or as being manifestly malnourished, they received parenteral nutritional supplementation (SmofKabiven Peripheral; Fresenius Kabi Austria GmbH, Graz, Austria) offering $800 \mathrm{kcal} / \mathrm{d}$ as well as $1.206 \mathrm{~L}$ of fluid supplementation for the 96-hour perioperative period. Laboratory parameters such as albumin, pseudocholinesterase (PCHE), and triglycerides were monitored at admission and discharge, and additionally albumin and triglycerides were monitored once a day during the intervention.

Intervention-associated local complications (eg, increased rate of intravenous accesses or local infections) and systemic complications (eg, hypervolemia and elevated liver enzymes or fatty acids) were documented. Further local and systemic complications as well as hospital mortality were recorded. Prefracture mobility was measured using the new mobility score as a validated predictor of long-term mortality and rehabilitation outcome in patients with hip fractures. ${ }^{30}$ The scores ranged between 0 and 3 (0, "not at all"; 1, "with 
help from another person"; 2, "with an aid"; and 3, "with no difficulty") for each function, resulting in a total score from 0 (indicating no walking ability at all) to 9 (indicating full independence). Our physiotherapists scored postfracture mobilization by assessing the following grades: 0, "no mobilization"; 1, "sitting"; 2, "standing"; 3, "walking"; and 4, "climbing stairs." The Timed Up and Go (TUG) test ${ }^{31}$ was used as well, if possible. Risk stratification for decubital ulcers was done according to the Braden Scale. ${ }^{32}$

We collected data in an Excel 2013 database (Microsoft Corporation, Redmond, WA, USA). We used double entry with a plausibility check to improve data quality. We used Predictive Analytics SoftWare Version 22.0 (SPSS Inc., Chicago, IL, USA) for descriptive statistics and explorative data analysis.

\section{Results}

We screened 96 patients; after identifying the patients who were cognitively impaired and who did not meet the exclusion criteria, we sought permission from the patients' legal guardians for inclusion. As a result, 25 qualified patients were identified; five of them were excluded due to their moribund status or their lack of the required legal guardianship. The baseline is given in Table 1. The sample included eleven women (median age: 87 years; age range: $74-91$ years) and nine men (median age: 82 years; age range: 73-89 years). The median Mini-Mental State Examination score at admission was 9.5 (range: 0-24). All patients in the sample were undernourished or at risk of malnutrition on one or both of the MNA or the NRS 2002. All the tests were interviewer administered, with the assistance of an accompanying relative or legal guardian. In some cases, such as for institutionalized patients, the relatives or legal guardians could not provide enough information. In these cases, the staff of the nursing home helped to acquire further information using their own knowledge or available medical records. The patients' median BMI was $23 \mathrm{~kg} / \mathrm{m}^{2}$ (range: $12.9-29.9 \mathrm{~kg} / \mathrm{m}^{2}$ ), with five patients being overweight and four patients being underweight. The median CC was $29.5 \mathrm{~cm}$ (range: 18-34 cm). All patients who were underweight according to BMI had diminished CC. Another eight patients had $\mathrm{CCs}>30 \mathrm{~cm}$. The mean Barthel Index was 40 (range: 20-95), and the mean American Society of Anesthesiologists' classification status was 3 (range: 2-4). Of the patients in the sample, three received prostheses and 17 received osteosynthesis. The mean hospital stay lasted 13 days (range: 7-17 days), including a mean of 1 day in the intensive care unit (range: 0-17 days). One patient spent 17 days in the intensive care unit before dying due to pneumonia and respiratory failure. The sample included 12 patients with nonsurgical complications (Table 2); the mortality rate was $10 \%$.

Table I Baseline data

\begin{tabular}{|c|c|c|c|c|c|c|c|c|c|}
\hline ID & Age (years) & Sex & ASA & MMSE & BMI $\left(\mathrm{kg} / \mathrm{m}^{2}\right)$ & $\mathrm{CC}(\mathrm{cm})$ & MNA & NRS 2002 & BI-A \\
\hline $\mathrm{I}$ & 89 & $\mathrm{~F}$ & 4 & 9 & 20.8 & 32 & 12 & 3 & 35 \\
\hline 2 & 78 & $\mathrm{~F}$ & 3 & 10 & 26.3 & 33.5 & 16 & 3 & 40 \\
\hline 3 & 82 & $M$ & 3 & 20 & 29.9 & 36 & 17 & 3 & 70 \\
\hline 4 & 82 & $M$ & 3 & 0 & 20.3 & 28 & 6.5 & 3 & 20 \\
\hline 5 & 77 & $\mathrm{~F}$ & 3 & 10 & 23.4 & 25 & 7.5 & 3 & 40 \\
\hline 6 & 80 & $\mathrm{~F}$ & 3 & 7 & 24 & 29 & 14 & 2 & 35 \\
\hline 7 & 90 & $\mathrm{~F}$ & 4 & 24 & 18 & 20 & 10 & 3 & 55 \\
\hline 8 & 91 & $\mathrm{~F}$ & 4 & 20 & 12.9 & 18 & 13 & 5 & 60 \\
\hline 9 & 87 & $M$ & 3 & 15 & 25.1 & - & 14.5 & 3 & 85 \\
\hline 10 & 87 & $\mathrm{~F}$ & 3 & 3 & 27.3 & 31 & 10.5 & 3 & 50 \\
\hline II & 75 & $\mathrm{~F}$ & 3 & 15 & 15.5 & 19 & 10 & 5 & 40 \\
\hline 12 & 82 & $M$ & 3 & 5 & - & 28 & 24.5 & 2 & 80 \\
\hline 13 & 73 & $M$ & 4 & 4 & 22.9 & 34 & 13 & 2 & 20 \\
\hline 14 & 88 & $M$ & 3 & 2 & 27 & 31 & 16.5 & 3 & 35 \\
\hline 15 & 86 & $\mathrm{~F}$ & 2 & 9 & 26.3 & 31 & 18.5 & 2 & 25 \\
\hline 16 & 89 & $F$ & 3 & 1 & 25 & - & 16 & 3 & 40 \\
\hline 17 & 85 & $M$ & 3 & 0 & 22.5 & 30 & 12 & 1 & 55 \\
\hline 18 & 74 & $\mathrm{~F}$ & 3 & 10 & 18.3 & 29 & II & 3 & 65 \\
\hline 19 & 89 & $M$ & 3 & 21 & 26.5 & 34.5 & 23.5 & 2 & 95 \\
\hline 20 & 81 & $M$ & 3 & 16 & 22.5 & 29 & 18.5 & 3 & 35 \\
\hline
\end{tabular}

Notes: Gray-shaded fields highlight patients who did not survive in patient stay. "-” Indicates missing value.

Abbreviations: ASA, American Society of Anesthesiologists; MMSE, Mini-Mental State Examination; BMI, body mass index; CC, calf circumference; MNA, Mini Nutritional Assessment; NRS 2002, Nutritional Risk Score; BI-A, Barthel Index at admission; F, female; M, male. 
Table 2 Analytical separation of complications

\begin{tabular}{ll}
\hline Complication & Number of patients \\
\hline Pleural effusion & $2^{\mathrm{a}}$ \\
Urinary tract infection & 5 \\
NSTEMI & $\mathrm{I}$ \\
Pneumonia & $2^{\mathrm{a}}$ \\
Pneumothorax & $\mathrm{I}$ \\
Clostridium difficile infection & $\mathrm{I}$ \\
Anemia & 2 \\
Death & 2 \\
\hline
\end{tabular}

Note: asame patient.

Abbreviation: NSTEMI, non-ST-segment elevation myocardial infarction.

Parenteral nutrition was started in all cases directly after admission and provided for 96 hours. Two patients did not tolerate peripheral venous line and therefore did not receive more than 48 hours of parenteral nutrition. The venous line was not replaced if a patient reacted with confusion or aggression (as in both cases mentioned earlier).

Hypoalbuminemia was defined as a serum albumin of $<36 \mathrm{mg} / \mathrm{dL} .{ }^{33}$ The median albumin level was $34 \mathrm{mg} / \mathrm{dL}$ (range: $18-41 \mathrm{mg} / \mathrm{dL}$ ) at admission and $29 \mathrm{mg} / \mathrm{dL}$ (range: $26-30 \mathrm{mg} / \mathrm{dL}$ ) at discharge. This difference was statistically significant (Figure 1A; $P=0.016$ ). A similarly significant drop was detected in PCHE (Figure 1B). Triglycerides ranged mostly in physiological or mild elevated levels. None of the patients showed triglycerides $>500 \mathrm{mmol} / \mathrm{L}$; only one had two measurements $>200 \mathrm{mmol} / \mathrm{L}$. All other patients did not pass $200 \mathrm{mmol} / \mathrm{L}$ during the intervention. The complete amounts are given in Table 3.

The median new mobility score for pretrauma mobility was only 0.5 (range: $0-5$ ). Postoperative assessments showed that only one patient could perform the TUG test.
The mobilization scores included some good results, with 15 patients achieving at least a standing position. The Braden Scale underlined the high risk of developing decubital ulcers, as 18 patients were in the high-risk group (Table 4).

\section{Discussion}

Although malnutrition is known to be a frequent finding in geriatric patients, data regarding cognitively impaired geriatric trauma patients are sparse, as this cohort is often excluded from nutritional supplementation studies. ${ }^{20-22}$

By present nutritional intervention pilot study, we aimed to detect the specific problems and difficulties related to screening, inclusion and nutritional intervention, and at least outcome measurement in this fragile, high-risk group of cognitively impaired geriatric trauma patients.

At first, some legal guardians were not available or not appointed at admission and therefore could not agree to participate at admission. Since ESPEN ${ }^{34}$ recommends screening for malnutrition to be an integrative part of geriatric assessment, including interventions for improvement of nutritional status in patients identified to be malnourished, a feasible study design for these patients should include the possibility for a subsequent approval when legal guardians are within reach.

Numerous tools are available in the literature to screen for malnutrition, but as mentioned in ESPEN's guidelines on nutrition in dementia, ${ }^{34}$ none of these tools have been specifically designed or validated for persons with dementia. Nevertheless, the MNA has shown wide acceptance among cognitively impaired patients, and the MNA Short Form has
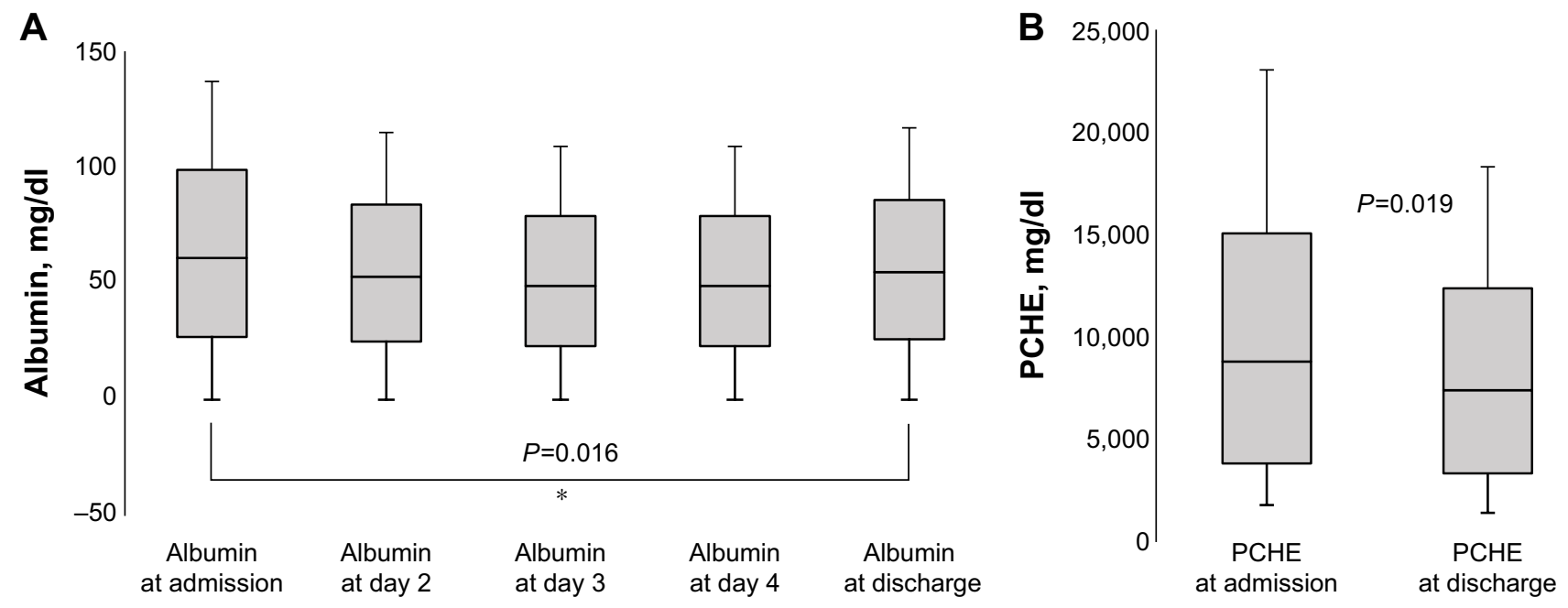

Figure I (A) Median albumin levels at admission; at days 2, 3, and 4 of nutritional supplementation; and at discharge. (B) Median PCHE = PCHE at admission and discharge. Notes: Data are given as median and quartiles. $* P \leq 0.05$.

Abbreviation: PCHE, pseudocholinesterase. 
Table 3 Analytical data of serological parameters

\begin{tabular}{lllllllll}
\hline Albumin (mg/dL) & Median & Range & PCHE (U/L) & Median & Range & Triglycerides (mmol/L) & Median & Range \\
\hline Admission & 34 & $18-4 \mid$ & Admission & 4,965 & $2,020-7,99 \mid$ & Admission & 77 & $42-25 \mid$ \\
Day 2 & 28 & $20-35$ & Day 2 & - & - & Day 2 & 73 & $28-436^{a}$ \\
Day 3 & 26 & $22-32$ & Day 3 & - & - & Day 3 & 42 & $40-38 I^{\text {a }}$ \\
Day 4 & 26 & $22-32$ & Day 4 & - & - & Day 4 & 78 & $42-187$ \\
Discharge & 29 & $29-31$ & Discharge & 4,065 & $1,910-5,945$ & Discharge & 106 & $54-\mid 86$ \\
\hline
\end{tabular}

Notes: PCHE was measured only at admission and discharge. ${ }^{B}$ Both amounts were measured in the same patient. "-" Indicates no planned blood analysis.

Abbreviation: PCHE, pseudocholinesterase.

been validated especially for older people and is reported to be used frequently in populations both with and without dementia. ${ }^{35-38}$ Both of the screening tools used, the MNA and NRS 2002, are reported to be, especially, suitable for patients with proximal femoral fractures..$^{39}$ Nevertheless, information about a patient's prefracture nutritional status was difficult and time consuming to determine when relatives were not present. Nevertheless, this could be accomplished in most cases, and since all the included patients were shown to be manifestly undernourished or at risk on at least one of the two tests, this study's data underline the importance of this topic.

Furthermore, we tried to add information through anthropometric and serological screening parameters. Recent data showed that higher BMI is associated with decreased risk of mortality ${ }^{40}$ but simultaneously more obese and older patients are known to be more likely to develop adverse outcomes following a primary total hip replacement. ${ }^{41}$ Concerning CC, a cutoff of $30.5 \mathrm{~cm}$ for both men and women is reported to provide a good diagnostic capacity. ${ }^{42}$ Our results showed a correlation of CC among underweight patients (BMI $<18 \mathrm{~kg} / \mathrm{m}^{2}$ ) but not among all patients. Since some patients suffered from cardiac failure, peripheral edemas may have influenced these measurements.

Despite increasing evidence that hepatic protein levels do not depend only on nutritional intake, these proteins continue to be used to assess patients' nutritional states and

\section{Table 4 Outcome scores}

\begin{tabular}{lll}
\hline Test & Item & Results \\
\hline TUG test & Possible & I patient -7 seconds \\
Mobilization & Not possible & 19 \\
& 0. No mobilization & 2 \\
& I. Sitting & 3 \\
& 2. Standing & 7 \\
& 3. Walking & 7 \\
NMS, median/range & 4. Climbing stairs & 1 \\
BS & & $0.5(0-5)$ \\
& $\geq 10$ points & 2 \\
\hline
\end{tabular}

Abbreviations: TUG, Timed Up and Go; NMS, new mobility score for in-hospital outcome; BS, Braden Scale. to diagnose malnutrition. ${ }^{43,44}$ Serum albumin levels at admission are known to be a significant independent predictor of complications in geriatric trauma patients. ${ }^{29}$ In our collective, one of eleven patients showing hypoalbuminemia at admission died during the study. Keeping in mind that four patients were shown to be underweight according to BMI, three of these patients had hypoalbuminemia and all of them were at risk or malnourished according to MNA and NRS 2002. BMI and albumin proved not to be suitable as the sole screening parameters for malnutrition in our cohort. These findings are in line with the current literature reporting that in the perioperative situation, neither hypoalbuminemia nor BMI is reliable for the diagnosis of protein energy malnutrition. ${ }^{45}$

The outcome parameters for the measurement of the success of short-term nutritional supplementation during hospitalization proved to be difficult to identify. Following patients' protein levels in serum was feasible, but as albumin has a long half-life of 18-20 days ${ }^{46}$ it may have reduced sensitivity for detection of recent changes in the nutritional state.

Subsequently, we observed that short-term parenteral supplementation as a crisis intervention did not prevent patients' albumin and PCHE levels from dropping during the 7-17 days between admission and submission. This finding is in line with other intervention studies. ${ }^{47}$ Albumin shows an immediate response to surgical stress, ${ }^{48-50}$ and the findings of a recent pilot study suggest that postoperative albumin decrease reliably quantifies the magnitude of a surgery. ${ }^{51}$ The underlying reasons for postoperative albumin decreases are summarized as an interplay of a decreased fractional synthesis rate, a capillary leak due to the metabolic stress response, ${ }^{52-54}$ and hemodilution as a potential confounder. Fractional albumin synthesis increases again during the early postoperative period proportionally to the degree of inflammation; additionally, production can be further stimulated by perioperative nutrition and nutrition being initiated before the operation, as done in our intervention. Recently, it has been published that isolated fracture of the femur elicits an inflammatory response in geriatric trauma patients similar to low injury severity in polytrauma patients. ${ }^{55}$ This may 
explain the decrease in albumin levels that were observed in our high-risk cohort despite nutritional supplementation. Maybe additional oral nutritional supplements (ONS) would prove the effects, as ONS already proved beneficial in gaining weight in frail or malnourished patients. Nevertheless, improvement in functional status or mortality by ONS was not seen in hip fracture or demented populations. ${ }^{56}$ In a meta-analysis of 22 trials, seven reported that nutritionally supplemented patients had shorter overall lengths of their hospital stays. ${ }^{3}$ In line with other publications, ${ }^{57-59}$ the mean length of stay in our cohort was 13 days but as diagnosisrelated groups system used in Germany requires a minimum of 13 days to determine the estimated costs of each stay, this parameter is difficult to interpret. ${ }^{60}$ Since the TUG test requires no special equipment or training, we tried to assess it in our cohort. This failed due to prefracture immobility and cognitive decline, which caused patients to simply not understand the instructions. Finally, the intervention-related complications were sparse; we had only few patients who did not tolerate venous line and there was no catheter-associated infection. Severe hyperlipidemia did not occur. Therefore, we can recommend parenteral nutritional intervention as a safe and feasible perioperative crisis intervention but may be not sufficient without further aftercare in this collective.

Our pilot study had some limitations. First, our local ethical authorities allowed including only a small number of patients for pilot study. As we primarily aimed to detect the pitfalls in inclusion of cognitively impaired patients, we did not have a control group. Therefore, we could not compare clinical courses of our patients to those without intervention. Besides, we had ethical concerns, depriving patients classified as malnourished from nutritional supplementation. Finally, two patients were not able to complete more than 48 hours of parenteral nutrition; this may have biased the laboratory outcome parameters.

\section{Conclusion}

Summing up the mentioned findings, cognitively impaired trauma patients showed to be especially at risk of malnutrition and at high risk of developing decubital ulcers and experiencing a comparatively high rate of nonsurgical complications. MNA and NRS 2002 proved to be feasible screening methods for identifying these patients. Because 96 hours of parenteral nutrition alone failed to bring out a significant improvement in our cohort, additional application of ONS could be considered in further clinical courses. Laboratory and functional outcome parameters for measuring successive supplementation surely need further evaluations involving randomized controlled trials.

\section{Acknowledgment}

This research received no specific grant from any funding agency in the public, commercial, or not-for-profit sectors.

\section{Author contributions}

All authors contributed toward data analysis, drafting and critically revising the paper and agree to be accountable for all aspects of the work.

\section{Disclosure}

The authors report no conflicts of interest in this work.

\section{References}

1. Sullivan DH, Sun S, Walls RC. Protein-energy undernutrition among elderly hospitalized patients: a prospective study. JAMA. 1999; 281(21):2013-2019.

2. Royal College of Physicians. Nutrition and Patients: A Doctor's Responsibility. London, England: Royal College of Physicians; 2003.

3. Avenell A, Handoll HHG. Nutritional supplementation for hip fracture aftercare in older people (review). Cochrane Database Syst Rev. 2010;1: $1-86$.

4. Paillaud E, Bories PN, Le Parco JC, Campillo B. Nutritional status and energy expenditure in elderly patients with recent hip fracture during a 2-month follow-up. Br J Nutr. 2000;83(2):97-103.

5. McWhirter JP, Pennington CR. Incidence and recognition of malnutrition in hospital. BMJ. 1994;308:945-948.

6. Weekes E. The incidence of malnutrition in medical patients admitted to hospital in south London. Proc Nutr Soc. 1999;58:126A.

7. Foss NB, Jensen PS, Kehlet H. Risk factors for insufficient preoperative oral nutrition after hip fracture surgery within a multi-modal rehabilitation program. Age Ageing. 2007;36(5):538-543.

8. Koren-Hakim T, Weiss A, Hershkovitz A, et al. The relationship between nutritional status of hip fracture operated elderly patients and their functioning, comorbidity and outcome. Clin Nutr. 2012;31(6):917-921.

9. Stenvall M, Berggren M, Lundstrom M, et al. A multidisciplinary intervention program improved the outcome after hip fracture for people with dementia - subgroup analyses of a randomized controlled trial. Arch Gerontol Geriatr. 2012;54(3):e284-e289.

10. Juliebø V, Krogseth M, Skovlund E, Engedal K, Ranhoff AH, Wyller TB. Delirium is not associated with mortality in elderly hip fracture patients. Dement Geriatr Cogn Disord. 2010;30(2):112-120.

11. Lundström M, Olofsson B, Stenvall M, et al. Postoperative delirium in old patients with femoral neck fracture: a randomized intervention study. Aging Clin Exp Res. 2007;19:178-186.

12. Chang CC, Roberts BL. Feeding difficulty in older adults with dementia. J Clin Nurs. 2008;17:2266-2274.

13. Belmin J. Practical guidelines for the diagnosis and management of weight loss in Alzheimer's disease: a consensus from appropriateness ratings of a large expert panel. J Nutr Health Aging. 2007;11(1):33-37.

14. White H, Pieper C, Schmader K, Fillenbaum G. Weight change in Alzheimer's disease. J Am Geriatr Soc. 1996;44(3):265-272.

15. Albanese E, Taylor C, Siervo M, Stewart R, Prince MJ, Acosta D. Dementia severity and weight loss: a comparison across eight cohorts. The 10/66 study. Alzheimers Dement. 2013;9(6):649-656.

16. Gambassi G, Landi F, Lapane KL, Sgadari A, Mor V, Bernabei R. Predictors of mortality in patients with Alzheimer's disease living in nursing homes. J Neurol Neurosurg Psychiatry. 1999;67(1):59-65.

17. Faxen-Irving G, Basun H, Cederholm T. Nutritional and cognitive relationships and long-term mortality in patients with various dementia disorders. Age Ageing. 2005;34(2):136-141.

18. Hedström M, Ljungqvist $\mathrm{O}$, Cederholm T. Metabolism and catabolism in hip fracture patients: nutritional and anabolic intervention - a review. Acta Orthop. 2006;77(5):741-747. 
19. Eneroth M, Olsson UB, Thorngren KG. Nutritional supplementation decreases hip fracture-related complications. Clin Orthop Relat Res. 2006; 451:212-217.

20. Gherini S, Vaughn BK, Lombardi AV, Mallory TH. Delayed wound healing and nutritional deficiencies after total hip arthroplasty. Clin Orthop Relat Res. 1993;293:188-195.

21. Russell L. The importance of patients' nutritional status in wound healing. Br J Nurs. 2001;10(6 suppl):S44-S49.

22. Koval KJ, Maurer SG, Su ET, Aharonoff GB, Zuckerman JD. The effects of nutritional status on outcome after hip fracture. J Orthop Trauma. 1999;13(3):164-169.

23. Anbar R, Beloosesky Y, Cohen J, et al. Tight calorie control in geriatric patients following hip fracture decreases complications: a randomized, controlled study. Clin Nutr. 2014;33(1):23-28.

24. Mundi S, Chaudhry H, Bhandari M. Systematic review on the inclusion of patients with cognitive impairment in hip fracture trials: a missed opportunity? Can J Surg. 2014;57(4):E141-E145.

25. Bastow MD, Rawlings J, Allison SP. Benefits of supplementary tube feeding after fractured neck of femur: a randomized controlled trial. Br Med J (Clin Res Ed). 1983;278:1589-1592.

26. Sullivan DH, Nelson CL, Klimberg VS, Bopp MM. Nightly enteral nutrition support of elderly hip fracture patients: a pilot study. $\mathrm{J} \mathrm{Am}$ Coll Nutr. 2004;23(6):683-691.

27. Volkert D, Chourdakis M, Faxen-Irving G, et al. ESPEN guidelines on nutrition in dementia. Clin Nutr. 2015;34(6):1052-1073.

28. Folstein MF, Folstein SE, McHugh PR. Mini-Mental State (a practical method for grading the state of patients for the clinician). J Psychiatr Res. 1975;12(3):189-198.

29. Haynes SR, Lawler PG. An assessment of the consistency of ASA physical status classification allocation. Anaesthesia. 1995;50(3): S195-S199.

30. Parker MJ, Palmer CR. A new mobility score for predicting mortality after hip fracture. J Bone Joint Surg Br. 1993;75:797-798.

31. Podsiadlo D, Richardson S. The timed "up \& go": a test of basic functional mobility for frail elderly persons. J Am Geriatr Soc. 1991;39(2): 142-148.

32. Bergstrom N, Braden BJ, Laguzza A, Holman V. The Braden Scale for predicting pressure sore risk. V Nurs Res. 1987;36(4):205-210.

33. Garwe T, Albrecht RM, Stoner JA, Mitchell S, Motghare P. Hypoalbuminemia at admission is associated with increased incidence of in-hospital complications in geriatric trauma patients. Am J Surg. 2015;212(1): 109-115

34. Volkert D, Chourdakis M, Faxen-Irving G, et al. ESPEN guidelines on nutrition in dementia. Clin Nutr. 2015;34(6):1052-1073.

35. van Bokhorst-de van der Schueren MAE, Guaitoli PR, Jansma EP, de Vet HCW. Nutrition screening tools: does one size fit all? A systematic review of screening tools for the hospital setting. Clin Nutr. 2014; 33(1):39-58.

36. Vandewoude M, Van Gossum A. Nutritional screening strategy in nonagenarians: the value of the MNA-SF (mini nutritional assessment short form) in NutriAction. J Nutr Health Aging. 2013;17(4):310.

37. Phillips MB, Foley AL, Barnard R, Isenring EA, Miller MD. Nutritional screening in community-dwelling older adults: a systematic literature review. Asia Pac J Clin Nutr. 2010;19(3):440-449.

38. Isaia G, Mondino S, Germinara C, et al. Malnutrition in an elderly demented population living at home. Arch Gerontol Geriatr. 2011; 53(3):249.

39. Murphy MC, Brooks CN, New SA, Lumbers ML. The use of the MiniNutritional Assessment (MNA) tool in elderly orthopaedic patients. Eur J Clin Nutr. 2000;54(7):555-562.

40. Garcia-Ptacek S, Kareholt I, Farahmand B, Cuadrado ML, Religa D, Eriksdotter M. Body-mass index and mortality in incident dementia: a cohort study on 11,398 patients from SveDem, the Swedish Dementia Registry. J Am Med Dir Assoc. 2014;15(6):447.e1-447.e7.
41. Mnatzaganian G, Ryan P, Norman PE, Davidson DC, Hiller JE. Use of routine hospital morbidity data together with weight and height of patients to predict in-hospital complications following total joint replacement. BMC Health Serv Res. 2012;12:380.

42. Bonnefoy M, Jauffret M, Kostka T, Jusot JF. Usefulness of calf circumference measurement in assessing the nutritional state of hospitalized elderly people. Gerontology. 2002;48(3):162-169.

43. Moshage HJ, Janssen JA, Franssen JH, Hafkenscheid JC, Yap SH. Study of the molecular mechanism of decreased liver synthesis of albumin in inflammation. J Clin Invest. 1987;79(6):1635-1641.

44. Fuhrman MP, Charney P, Mueller CM. Hepatic proteins and nutrition assessment. J Am Diet Assoc. 2004;104(8):1258-1264.

45. Drevet $\mathrm{S}$, Bioteau $\mathrm{C}$, Mazière $\mathrm{S}$, et al. Prevalence of protein-energy malnutrition in hospital patients over 75 years of age admitted for hip fracture. Orthop Traumatol Surg Res. 2014;100(6):669-674.

46. Foster MR, Heppenstall RB, Friedenberg ZB, Hozack WJ. A prospective assessment of nutritional status and complications in patients with fractures of the hip. J Orthop Trauma. 1990;4(1):49-57.

47. Botella-Carretero JI, Iglesias B, Balsa JA, Zamarrón I, Arrieta F, Vázquez C. Effects of oral nutritional supplements in normally nourished or mildly undernourished geriatric patients after surgery for hip fracture: a randomized clinical trial. JPEN J Parenter Enteral Nutr. 2008;32(2):120-128.

48. Smeets HJ, Kievit J, Dulfer FT, Hermans J, Moolenaar AJ. Analysis of post-operative hypalbuminaemia: a clinical study. Int Surg. 1994; 79(2):152-157.

49. Ryan AM, Hearty A, Prichard RS, Cunningham A, Rowley SP, Reynolds JV. Association of hypoalbuminemia on the first postoperative day and complications following esophagectomy. J Gastrointest Surg. 2007;11(10):1355-1360.

50. Fleck A, Raines G, Hawker F, et al. Increased vascular permeability: a major cause of hypoalbuminaemia in disease and injury. Lancet. 1985;325(8432):781-784.

51. Hübner M, Mantziari S, Demartines N, Pralong F, Coti-Bertrand P, Schäfer M. Postoperative albumin drop is a marker for surgical stress and a predictor for clinical outcome: a pilot study. Gastroenterol Res Pract. 2016;2016:8743187.

52. Fleck A, Colley CM, Myers MA. Liver export proteins and trauma. Br Med Bull. 1985;41(3):265-273.

53. Hülshoff A, Schricker T, Elgendy H, Hatzakorzian R, Lattermann R. Albumin synthesis in surgical patients. Nutrition. 2013;29(5): 703-707.

54. Russell JA. Management of sepsis. $N$ Engl J Med. 2006;355(16): 1699-1713.

55. Vester H, Huber-Lang MS, Kida Q, et al. The immune response after fracture trauma is different in old compared to young patients. Immun Ageing. 2014;11(1):20.

56. Gammack JK, Sanford AM. Caloric supplements for the elderly. Curr Opin Clin Nutr Metab Care. 2015;18(1):32-36.

57. Buecking B, Wack C, Oberkircher L, Ruchholtz S, Eschbach D. Do concomitant fractures with hip fractures influence complication rate and functional outcome? Clin Orthop Relat Res. 2012;470(12): 3596-3606.

58. Eschbach DA, Oberkircher L, Bliemel C, Mohr J, Ruchholtz S, Buecking B. Increased age is not associated with higher incidence of complications, longer stay in acute care hospital and in hospital mortality in geriatric hip fracture patients. Maturitas. 2013;74(2):185-189.

59. AQUA [home page on the Internet]. [Institut für angewandte Qualitätsförderung und Forschung im Gesundheitswesen]. Bundesauswertung zum Erfassungsjahr 2011. 17/1 - Hüftgelenksnahe Femurfraktur. Qualitätsindikatoren. 2012. Available from: http://www.aqua-institut.de. Accessed May 31, 2012.

60. Lawrence TM, White CT, Wenn R, Moran CG. The current hospital costs of treating hip fractures. Injury. 2005;36:88-91. 


\section{Publish your work in this journal}

Clinical Interventions in Aging is an international, peer-reviewed journal focusing on evidence-based reports on the value or lack thereof of treatments intended to prevent or delay the onset of maladaptive correlates of aging in human beings. This journal is indexed on PubMed Central, MedLine,

CAS, Scopus and the Elsevier Bibliographic databases. The manuscript management system is completely online and includes a very quick and fair peer-review system, which is all easy to use. Visit http://www.dovepress. com/testimonials.php to read real quotes from published authors. 